\title{
Article \\ Future Thinking Priming Especially Effective at Modifying Delay Discounting Rates among Cigarette Smokers
}

\author{
Alina Shevorykin ${ }^{1, *}$, Warren K. Bickel ${ }^{2}$, Ellen Carl ${ }^{1}$ and Christine E. Sheffer ${ }^{1} \mathbb{D}$ \\ 1 Department of Health Behavior, Roswell Park Comprehensive Cancer Center, Buffalo, NY 14203, USA; \\ Ellen.Carl@RoswellPark.org (E.C.); Christine.Sheffer@RoswellPark.org (C.E.S.) \\ 2 Virginia Tech, The Fralin Biomedical Research Institute at VTC, Roanoke, VA 24016, USA; \\ wkbickel@vtc.vt.edu \\ * Correspondence: alina.shevorykin@RoswellPark.org
}

Citation: Shevorykin, A.; Bickel, W.K.; Carl, E.; Sheffer, C.E. Future Thinking Priming Especially Effective at Modifying Delay Discounting Rates among Cigarette Smokers. Int. J. Environ. Res. Public Health 2021, 18, 8717. https://doi.org/10.3390/ ijerph18168717

Academic Editor: Flora Tzelepis

Received: 23 June 2021

Accepted: 13 August 2021

Published: 18 August 2021

Publisher's Note: MDPI stays neutral with regard to jurisdictional claims in published maps and institutional affiliations.

Copyright: (c) 2021 by the authors. Licensee MDPI, Basel, Switzerland. This article is an open access article distributed under the terms and conditions of the Creative Commons Attribution (CC BY) license (https:/ / creativecommons.org/licenses/by/ $4.0 /)$

\begin{abstract}
Background: Tobacco use remains one of the world's greatest preventable causes of death and disease. While most smokers want to quit, few are successful, highlighting a need for novel therapeutic approaches to support cessation efforts. Lower delay discounting (DD) rates are associated with increased smoking cessation success. Future thinking priming (FTP) reliably reduces DD rates in large populations. Smokers consistently discount more than nonsmokers, and evidence suggests that changes in DD rates are rate dependent. This study examined whether smoking status moderated the effect of FTP on DD rates and, if so, if the moderation effect could be attributed to differences in baseline rates of DD. Methods: Moderation analysis was conducted to determine whether the effect of FTP, versus neutral priming (NP), on DD differed among smokers and nonsmokers. Results: Smoking status moderated the effect of condition (FTP vs. NP) on postintervention DD scores $(b=-0.2919, p=0.0124)$ and DD change scores $(b=-0.2975, p=0.0130)$. There was no evidence of rate dependence effects in the current sample. Conclusions: FTP had a greater effect on decreasing DD rates among smokers than nonsmokers. FTP is effective and simple to administer, which makes it a promising therapeutic approach for aiding smoking cessation.
\end{abstract}

Keywords: tobacco; impulsivity; priming; addiction; rate dependent; delayed discounting

\section{Introduction}

"The future interests me-I'm going to spend the rest of my life there."-Mark Twain. Despite the success of tobacco control efforts, tobacco use remains one of the most significant preventable causes of death and disease in the world today [1]. Annually, cigarette smoking alone causes more than 8 million deaths worldwide, over 600,000 of whom die from secondhand smoke [2-8]. In the US, smoking cigarettes causes nearly half a million deaths annually and over $30 \%$ of all cancer deaths $[9,10]$. In the US, most individuals who smoke express the desire to quit, and over half make at least one quit attempt nearly every year, but within 6-12 months, over 90\% reverse this decision despite significant effort [11]. This pernicious conundrum remains one of the most significant public health challenges today, calling for innovative therapeutic targets and novel approaches to support efforts to quit smoking [10].

Smoking cigarettes is a highly reinforcing experience for many individuals, and achieving long-term abstinence from smoking is a process whereby individuals must repeatedly choose options other than the immediate reinforcing experience of smoking. While the biological rewards (dopamine release) of cigarette smoking are not as significant as those of other drugs, the fact that smoking is so repetitive, and so often performed in conjunction with other activities, increases the association of those rewards with many activities engaged in on a daily basis, which both enhances the pleasure and the motivation derived from the activities and the reinforcing nature of smoking [12,13]. Delay discounting (DD) describes the degree to which the reinforcer's subjective value declines as the time 
to receipt increases. Most humans and many animals prefer immediate reinforcement but are willing to wait for a period of time for rewards that are perceived to be of more value [14-17]. Individuals who smoke demonstrate higher DD rates than individuals who do not, suggesting that, for smokers, reinforcers lose their value quickly when received outside the temporal window for which they are valued [2,3,6-8,18-23]. Good health, long life, and prudent far-sighted health-related decision-making are all temporally distant reinforcers. Among smokers, lower DD rates predict greater success at achieving and maintaining abstinence from smoking [24-29]. DD rate is also modifiable [2,6,26,27,30-34], and thus has become a novel therapeutic target in the treatment of tobacco dependence and other unhealthy behaviors.

Methods to decrease DD rates include framing techniques intended to alter the temporal window in which decisions are made [35]. Episodic future thinking is a framing technique that shows promise for reducing DD rates concurrently with other health behaviors, including cigarette smoking [8,36-40]. Future thinking priming (FTP) is another framing technique administered remotely that reliably reduces DD rates in large populations [41,42]. Framing techniques have been shown to impact the brain via the activation of neural networks involved in decision-making and prospective thinking, resulting in reductions in DD [43-46].

The effect of FTP on DD rates has been replicated in two studies and with multiple measures of DD with samples that include smokers and nonsmokers [41,42]. However, smokers consistently discount more than nonsmokers [47]. Therefore, understanding whether and how FTP specifically impacts DD rates among individuals who smoke is critical, and should be conducted prior to examining the therapeutic potential of FTP for cigarette smoking. For instance, the higher DD rates found among smokers might be less modifiable given that they appear to be so strongly associated with smoking status. On the other hand, evidence suggests that changes in DD rates are rate dependent [48-52], which suggests that FTP might have a greater impact on smokers, for whom there is more room for change in DD rates.

This study examined whether smoking status moderated the effect of FTP on DD rates and then examined if any differences found could be attributed to rate dependency. This is a secondary analysis of a randomized controlled trial in which FTP significantly decreased DD rates in a large sample of participants [42]. Given the evidence for rate dependence, we hypothesized that FTP would have a greater effect on individuals who smoke than those who do not smoke, and that this would be due to a rate-dependent difference in baseline measures of DD.

\section{Materials and Methods}

\subsection{Participants}

Adult Amazon Mechanical Turk (MTurk) workers (age $\geq 18$ years) who spoke English and resided in North America were eligible to participate. The study was approved by the Institutional Review Boards of City University of New York (\#680011-1) and Roswell Park Comprehensive Cancer Center (\#BDR082917). Informed consent was obtained from all participants. Data was collected in 2016. MTurk is an online worker platform. MTurk research participants provided responses comparable to those of laboratory participants [53-56].

\subsection{Study Design and Procedures}

In this study, we conceptualized smoking status as a moderator and conducted a moderation analysis to determine whether the relation between the conditions (FTP, NP) and the dependent variable (DD) was moderated by smoking status.

This is a secondary data analysis of a study that compared participants randomized to FTP or neutral priming (NP) in a pre/post-test control group design [42]. Participants ( $n=1532)$ were enrolled and completed baseline measures. Two weeks later, they were randomized, completed the FTP or NP tasks as assigned, and administered the postintervention assessments. 


\subsection{The Future Thinking Priming and Neutral Tasks}

The FTP stimuli consisted of 10 future-oriented words and phrases: "future", "selfdiscipline", "willpower", "self-control", "long-term", "save", "planned", and "investment". NP stimuli consisted of 10 words and phrases that reflected a neutral focus and were shown to have no effect on DD (e.g., "pale", "informative", "dispassionate", "formal", etc.). Participants were first instructed to write 10 different sentences describing themselves and incorporating at least one of the words provided. After submitting the sentences, participants were instructed to write a short paragraph (not exceeding 250 words) about themselves, incorporating all the words/phrases provided.

\subsection{Measures}

Standard sociodemographic measures were collected at baseline, including sex, age, race, ethnicity, education, and income. Additionally, tobacco use (number of cigarettes smoked per day) and alcohol use (number of alcoholic drinks per week) were collected. Because priming effects are influenced by social self-monitoring [57], we administered the self-monitoring scale. High social self-monitors may initially respond to priming stimuli in a manner consistent with the prime, but they are less likely to maintain primed behaviors because they tend to shift behaviors to match social expectations [57]. Time perspective (future-oriented or not) was assessed with the time perspective questionnaire [58]. Perceived social status (SSS) was measured by the MacArthur Scale of Subjective Social Status [59].

DD was the primary outcome measure. DD of USD 100 was assessed by the 5-Trial adjusting delay discounting task [60]. The 5-Trial task is an interactive instrument that automatically adjusts to respondents' choices to produce a result after a maximum of five trials [60]. Respondents were asked on the first trial whether they would prefer USD 50 now or USD 100 in three weeks. If the immediate option is selected, then the second trial shortens the delay to one day (USD 50 now or USD 100 in one day). If the delayed option is selected on the first trial, then the second trial lengthens the delay (i.e., USD 50 now or USD 100 in two years). Delays on all subsequent trials are adjusted based on responses from the preceding trial. The 5-trial task output was expressed as the natural logarithm of $\mathrm{k}$ in Mazur's hyperbolic discounting model, with $\mathrm{k}$ increasing as the preference for smaller sooner rewards increases [17]. Lower $\mathrm{k}$ values mean that individuals are more willing to wait for a larger reward.

\subsection{Data Analysis}

The analysis was carried out using IBM SPSS, Version 23 (IBM Corp., Armonk, NY, USA). Descriptive analyses were conducted to characterize the sample. One-way analysis of variance (ANOVA) and $\chi^{2}$ analysis were used to examine characteristic differences between smokers and nonsmokers. Statistically significant differences between the smokers and nonsmokers were included in the final models to control for baseline differences between the groups.

Moderation analysis was conducted using Hayes PROCESS v3.5.3 with bootstrapping at 1000 samples to examine potential moderation of smoking status on the effects of FTP on DD. We used two methods of conceptualizing the outcome: (1) DD post-intervention, and (2) change in DD (change = post interventions - baseline). Each outcome was analyzed in a separate model.

In the two models, condition (FTP vs. NP) was entered as a fixed variable, smoking status (smoker vs. nonsmoker) was entered as the moderator, and partner status, income, education, alcoholic drinks, and SSS were entered as covariates to control for baseline differences between smokers and nonsmokers. In the first model, baseline DD rate was also entered to be consistent with Blomqvist's method of controlling for the baseline measure of interest in the regression analyses [61]. Smoking status was considered a significant moderator if the interaction between smoking status and condition was significant for one or both smoking status categories. If the overall interaction between condition and 
smoking status was below $p<0.10$, following the guidance from Hayes, further probing was performed to measure the effects of this interaction on different levels of the moderator [62].

The Oldham correlation method was used to assess rate dependence overall and in smokers versus nonsmokers, using the following equation where $x$ is the baseline measure, $y$ is the post-intervention measure, $s^{2} x$ is baseline variance, $s^{2} y$ is post-test variance, and $r_{x y}$ is the correlation between baseline and post-intervention:

$$
\text { Oldham } \operatorname{Corr}\left((x-y), \frac{(x+y)}{2}\right)=\frac{s_{x}^{2}-s_{y}^{2}}{\sqrt{\left(s_{x}^{2}+s_{y}^{2}\right)^{2}-4 r_{x y}^{2} s_{x}^{2} s_{y}^{2}}}
$$

The Oldham correlation method was chosen because it was used to successfully identify rate dependence in DD in other studies and because it removes mathematical coupling, regression to the mean, and mathematical bias $[51,53,63]$. If the Oldham correlation is above 0.3 , the comparison is considered rate dependent $[50,51,53,64]$.

\section{Results}

\subsection{Participants}

Participants' ( $n=1532$ ) mean age was 35.7 years (SD 11.3); $54.8 \%$ were female; $82.5 \%$ were White; and about half were partnered (58.7\%). Two-thirds attended at least some college (65.9\%). Annual household incomes ranged from <USD 10,000 (5.1\%) to >USD 99,000 $(14.3 \%)$. The mean score for self-monitoring was intermediate $(\mathrm{M}=10.7, \mathrm{SD}=4.7)$. In the parent study, no characteristic differences among participants randomized to the FTP and NP conditions were found with the exception of other tobacco use (FTP $14.6 \%$ versus NP $\left.10.7 \% ; \chi^{2}=5.21, p=0.02\right)[42]$.

About one-fifth $(22 \% ; n=333)$ of participants reported smoking $>0$ cigarettes per day and were considered smokers. Nonsmokers were more likely to be partnered than smokers (61\% vs. 52\%); nonsmokers had significantly more education, higher income, and higher SSS than smokers. Smokers reported significantly more alcoholic drinks per week than nonsmokers (5.13 vs. 2.73). See Table 1 for details. 
Table 1. Participant characteristics.

\begin{tabular}{|c|c|c|c|c|c|}
\hline \multirow{2}{*}{\multicolumn{2}{|c|}{ Characteristic/Variable }} & \multirow[b]{2}{*}{$\begin{array}{c}\text { Range, Level, } \\
\text { Category }\end{array}$} & \multicolumn{2}{|c|}{ Mean (SD) or Percent (N) } & \multirow[b]{2}{*}{$\chi^{2}$ or $\mathrm{F}$} \\
\hline & & & $\begin{array}{l}\text { Nonsmokers } \\
\quad(n=1199)\end{array}$ & $\begin{array}{l}\text { Smokers } \\
(n=333)\end{array}$ & \\
\hline \multirow{12}{*}{ Sociodemographic } & Sex & Female & $55.96(671)$ & $50.75(169)$ & $\chi^{2}=2.859, p=0.091$ \\
\hline & Age & $18-74$ & $35.40(11.27)$ & $36.74(11.201)$ & $\mathrm{F}=3.714, p=0.054$ \\
\hline & \multirow{3}{*}{ Race } & White & $81.81(981)$ & $84.98(284)$ & \multirow{3}{*}{$\chi^{2}=3.361, p=0.339$} \\
\hline & & Black & $6.26(75)$ & $6.31(21)$ & \\
\hline & & Other & $5.92(71)$ & $5.11(17)$ & \\
\hline & Hispanic & Yes & $6.42(77)$ & $6.91(23)$ & $\chi^{2}=3.361, p=0.751$ \\
\hline & Partner status * & Partnered & $60.71(728)$ & $51.65(172)$ & $\chi^{2}=8.838, p=0.003$ \\
\hline & Education in years * & $1-28$ & $15.81(2.686)$ & $14.62(2.611)$ & $\mathrm{F}=51.561, p<0.001$ \\
\hline & \multirow{4}{*}{ Annual household income * } & $<$ USD 24,999 & $17.10(205)$ & $28.53(95)$ & \multirow{4}{*}{$\chi^{2}=52.556, p<0.001$} \\
\hline & & USD 25,000-USD 49,999 & $28.86(346)$ & $35.74(119)$ & \\
\hline & & USD 75,000-USD 99,999 & $15.01(180)$ & $5.71(19)$ & \\
\hline & & >USD 100,000 & $16.18(194)$ & $7.51(25)$ & \\
\hline Alcohol use & Number of drinks per week* & $0-70$ & $2.73(5.155)$ & $5.13(8.049)$ & $\mathrm{F}=43.077, p<0.001$ \\
\hline \multirow{3}{*}{ Psychosocial } & Self-monitoring scale & $0-25$ & $10.59(4.598)$ & $11.01(4.960)$ & $\mathrm{F}=2.157, p<0.142$ \\
\hline & Time perspective & Future oriented & $66.31(795)$ & $63.96(213)$ & $\chi^{2}=0.635, p=0.426$ \\
\hline & SSS * & $0-10$ & $4.91(1.839)$ & $4.17(1.838)$ & $\mathrm{F}=41.979, p<0.001$ \\
\hline
\end{tabular}




\subsection{Moderation Effects}

Delay discounting post-intervention. The overall model for the moderation effect of smoking status on post-test DD rate was significant $\left(\mathrm{R}^{2}=0.6690, \mathrm{~F}=341.758, p<0.001\right)$. The interaction between condition and smoking status was less than $0.10(b=-0.2437$, $p=0.0651)$. Probing revealed that this effect was significant for smokers $(b=-0.2919$, $p=0.0124)$. See Table 2 and Figure 1.

Table 2. Moderating effect of smoking status on post-intervention delay discounting rate.

\begin{tabular}{|c|c|c|c|c|c|c|c|c|}
\hline \multirow{2}{*}{ Outcome Measure } & \multirow{2}{*}{\multicolumn{2}{|c|}{ Factors/Variables }} & \multirow{2}{*}{ B } & \multirow{2}{*}{ SE } & \multirow{2}{*}{$\mathbf{t}$} & \multirow{2}{*}{$p$} & \multicolumn{2}{|c|}{$95 \% \mathrm{CI}$} \\
\hline & & & & & & & Lower & Upper \\
\hline \multirow{11}{*}{$\begin{array}{l}\text { Post-intervention delay } \\
\text { discounting rate }\end{array}$} & \multirow{2}{*}{$\begin{array}{l}\text { Interaction + } \\
\text { effects }\end{array}$} & nonsmokers & -0.0482 & 0.0616 & -0.7836 & 0.4334 & -0.1690 & 0.0725 \\
\hline & & smokers & -0.2919 & 0.1168 & -2.499 & 0.0124 & -0.5209 & -0.0629 \\
\hline & \multicolumn{2}{|l|}{ Constant } & -0.5631 & 0.1964 & -2.8672 & 0.0042 & -0.9483 & -0.1779 \\
\hline & \multicolumn{2}{|l|}{ Condition } & -0.0486 & 0.0616 & -0.7901 & 0.4296 & -0.1694 & 0.0721 \\
\hline & \multicolumn{2}{|c|}{ Smoking status } & 0.3077 & 0.0968 & 3.1777 & 0.0015 & 0.1177 & 0.4976 \\
\hline & \multicolumn{2}{|c|}{$\begin{array}{l}\text { Baseline delay discounting } \\
\text { rate }\end{array}$} & 0.8579 & 0.0163 & 52.6498 & 0.0000 & 0.8259 & 0.8898 \\
\hline & \multicolumn{2}{|c|}{ Partnered status } & 0.0095 & 0.0592 & 0.1598 & 0.8731 & -0.1066 & 0.1256 \\
\hline & \multicolumn{2}{|l|}{ Education } & -0.0192 & 0.0106 & -1.8075 & 0.0709 & -0.0401 & 0.0016 \\
\hline & \multicolumn{2}{|l|}{ Income } & -0.0076 & 0.0183 & -0.4139 & 0.6790 & -0.0436 & 0.0284 \\
\hline & \multicolumn{2}{|c|}{$\begin{array}{l}\text { Alcohol (number of drinks } \\
\text { per week) }\end{array}$} & -0.0057 & 0.0046 & -1.2234 & 0.2214 & -0.0147 & 0.0034 \\
\hline & \multicolumn{2}{|c|}{ Perceived social status (SSS) } & 0.0039 & 0.0183 & 0.2125 & 0.8317 & -0.0320 & 0.0398 \\
\hline
\end{tabular}

+ Interaction is the conditional effects of the condition type (FTP vs. NP) based on the moderator variable (nonsmokers vs. smokers).

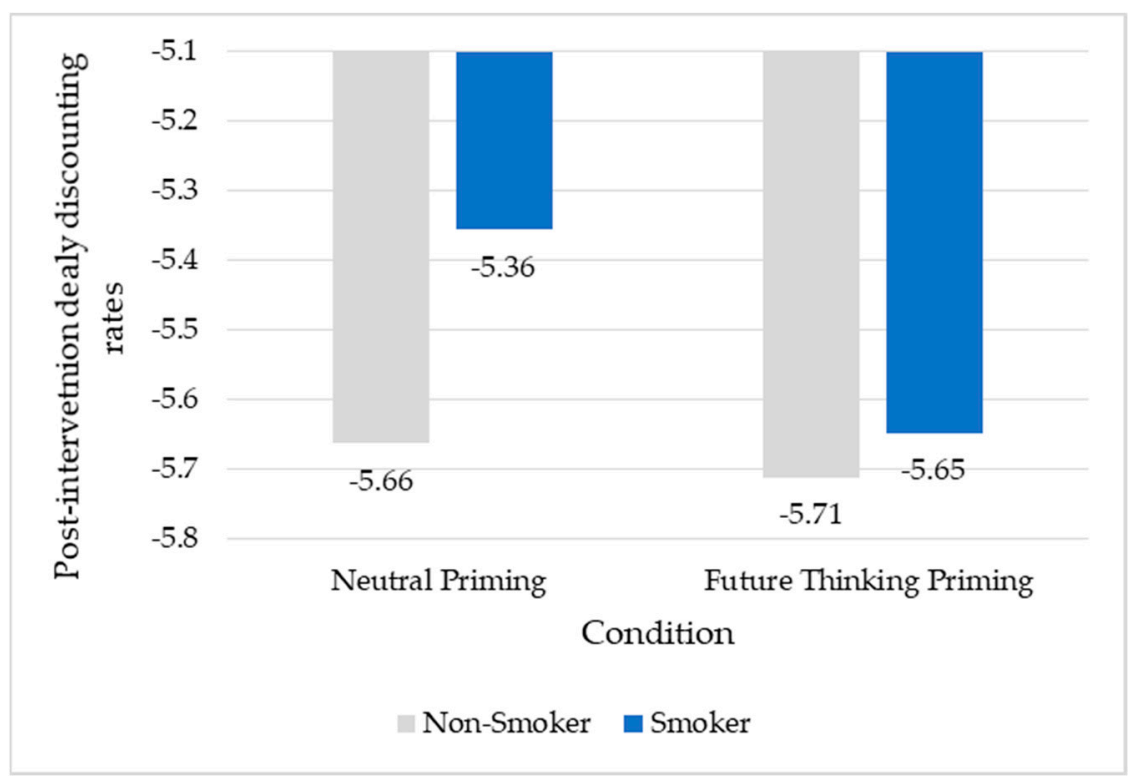

Figure 1. Future thinking priming appears to have a greater effect on smokers than nonsmokers.

Change in delay discounting. The overall model for the moderation effect of smoking status on DD change score was not significant $\left(R^{2}=0.0070, F=1.3334, p=0.2223\right)$. The interaction between condition and smoking status was less than $0.10(\mathrm{~b}=-0.2525, p=0.0620)$. Probing revealed this effect was significant for smokers $(b=-0.2975, p=0.0130)$ (see Table 3 and Figure 2). 
Table 3. Moderating effect of smoking status on change in delay discounting score.

\begin{tabular}{|c|c|c|c|c|c|c|c|c|}
\hline \multirow{2}{*}{ Outcome Measure } & \multirow{2}{*}{\multicolumn{2}{|c|}{ Factors/Variables }} & \multirow{2}{*}{$\mathbf{b}$} & \multirow{2}{*}{ SE } & \multirow{2}{*}{$\mathbf{t}$} & \multirow{2}{*}{$P$} & \multicolumn{2}{|c|}{$95 \% \mathrm{CI}$} \\
\hline & & & & & & & Lower & Upper \\
\hline \multirow{10}{*}{$\begin{array}{l}\text { The difference between } \\
\text { post-intervention and } \\
\text { baseline delayed } \\
\text { discounting rate }\end{array}$} & \multirow{2}{*}{$\begin{array}{l}\text { Interaction + } \\
\text { effects }\end{array}$} & nonsmokers & -0.0450 & 0.0631 & -0.7134 & 0.4757 & -0.1687 & 0.0787 \\
\hline & & smokers & -0.2975 & 0.1196 & -2.4872 & 0.0130 & -0.5321 & -0.0629 \\
\hline & \multicolumn{2}{|l|}{ Constant } & 0.0004 & 0.1900 & 0.0020 & 0.9984 & -0.3723 & 0.3730 \\
\hline & \multicolumn{2}{|l|}{ Condition } & -0.0450 & 0.0631 & -0.7134 & 0.4757 & -0.1687 & 0.0787 \\
\hline & \multicolumn{2}{|c|}{ Smoking status } & 0.2211 & 0.0987 & 2.2410 & 0.0252 & 0.0276 & 0.4146 \\
\hline & \multicolumn{2}{|l|}{ Partner } & 0.0307 & 0.0606 & 0.5060 & 0.6129 & -0.0882 & 0.1495 \\
\hline & \multicolumn{2}{|l|}{ Education } & -0.0097 & 0.0108 & -0.8933 & 0.3718 & -0.0309 & 0.0116 \\
\hline & \multicolumn{2}{|l|}{ Income } & 0.0032 & 0.0188 & 0.1729 & 0.8628 & -0.0335 & 0.0400 \\
\hline & \multicolumn{2}{|c|}{$\begin{array}{l}\text { Alcohol (number of drinks } \\
\text { per week) }\end{array}$} & -0.0057 & 0.0047 & -1.2065 & 0.2278 & -0.0150 & 0.0036 \\
\hline & \multicolumn{2}{|c|}{ Perceived social status (SSS) } & 0.0055 & 0.0188 & 0.2911 & 0.7710 & -0.0313 & 0.0423 \\
\hline
\end{tabular}

+ Interaction is the conditional effects of the condition type (FTP vs. NP) based on the moderator variable levels (nonsmokers vs. smokers).

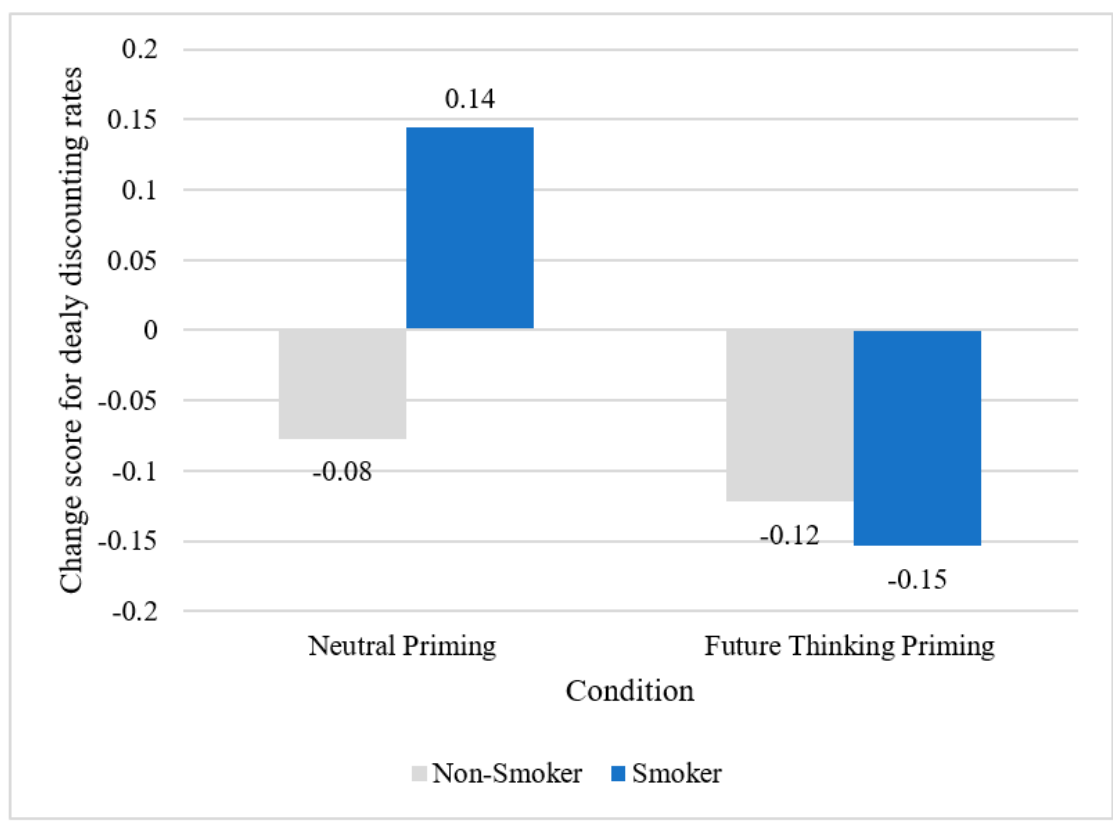

Figure 2. Future thinking priming produced larger change in delayed discounting rate than neutral priming among smokers.

\subsection{Rate-Dependence Effects}

No evidence of rate dependence was found. All Oldham correlations were below the 0.3 threshold. The overall DD outcomes showed an Oldham correlation of -0.113 ; DD among smokers showed an Oldham correlation of -0.010 ; DD among nonsmokers showed an Oldham correlation of -0.140 .

\section{Discussion}

Our findings indicate that a one-time remote administration of FTP decreased DD among individuals who smoked cigarettes. The FTP task had a greater effect on DD rates among individuals who smoked cigarettes than among those who did not. This suggests that FTP can modify DD rates among smokers, which enhances its therapeutic potential as a novel intervention to reduce DD and concurrently reduce cigarette consumption among smokers, similar to episodic future thinking. Our robust approach examined the moderating effects of smoking status on the effects of FTP on DD rates, using two different 
methods to account for baseline DD rates. Smoking status had a significant moderating effect in both models, which reinforces the reliability and validity of the findings.

FTP shows promise for development into a novel intervention to support smoking cessation. More research is needed to determine if FTP can decrease cigarette consumption as it decreases DD rates and to determine whether repeated exposure provides cumulative effects. Determination of optimal exposure patterns to support short- and long-term cessation is needed prior to efficacy testing.

If found to support smoking cessation, FTP has the potential to be disseminated widely with minimal infrastructure, which bodes well for potential reach. The FTP task was developed and tested via remote administration using an easily accessible survey program such as Qualtrics or RedCap. Individuals' engagement in the FTP task is practical and relatively undemanding. Individuals can engage in the task via a link sent by text or email and complete the task on a computer or mobile device.

Given the role of temporal distance in the subjective value of reinforcers, temporal orientation is increasingly being recognized as an important factor in attaining and maintaining abstinence from smoking. Efforts to develop novel interventions that target DD are gaining traction. These findings support previous research focused on DD as a therapeutic target in the treatment of tobacco use $[2,3,6-8]$ and represent the next step in the examination of FTP as an effective intervention.

We did not find rate-dependence effects, which might be indicative of the characteristics of the sample. Rate dependence is understudied, but we believe the process of calculating rate dependence is accessible, and future studies should continue to investigate rate dependence as part of the standard procedure $[48,49,51,52,65]$.

This study has several important strengths. First, the current sample was relatively large and representative, which increases the generalizability of findings. Second, results were replicated in two different models, which reduces the likelihood of potential model error or bias. Third, the rigorous design of the parent study helped ensure participant understanding of instructions and accuracy of measurements. Fourth, the current study addresses rate-dependence effects, which has recently been recognized as a methodological standard in research on treatment effectiveness $[49,51,52,65]$. Finally, the fact that the current study is a secondary data analysis helps increase the impact of the parent study and expands the research knowledge by investigating additional hypotheses cost-effectively and efficiently, as well as helping identify differences in treatment among subgroups of the parent study, which in turn can inform tailoring of group-specific treatments $[64,66]$.

This study has several limitations as well. The moderating effect of smoking status on the effects of FTP on DD rates might be explained by an unknown third factor, for example, having a higher income bracket might contribute to more future thinking orientation in general. Although relatively large, the sample sizes were different for nonsmokers and smokers. This might have contributed to a lack of significance in the overall interactions. There was no conditional effect for nonsmokers and they were a much larger group. Therefore, their weight in the standard error was greater. Finally, smoking status is a self-selected characteristic which ultimately may have resulted in some differences in psychosocial measures, even though these were controlled statistically in all models.

\section{Conclusions}

The current study showed that one-time administration of FTP had a greater effect on decreasing DD rates among smokers than nonsmokers. The FTP is a simple task accessible remotely on a wide variety of devices. The FTP task has potential to be developed as a therapeutic support for smoking cessation.

Author Contributions: Conceptualization, A.S., C.E.S., W.K.B., and E.C.; methodology, A.S., C.E.S., W.K.B., and E.C.; formal analysis, A.S.; investigation, C.E.S.; resources, A.S.; data curation, C.E.S.; writing-original draft preparation, A.S.; writing-review and editing, A.S., W.K.B., C.E.S., and E.C.; visualization, A.S.; supervision, W.K.B., and C.E.S.; project administration, C.E.S.; funding acquisition, C.E.S. All authors have read and agreed to the published version of the manuscript. 
Funding: This research was funded by the National Institute on Minority Health and Health Disparities (R01 MD007054 PI: Sheffer), the National Cancer Institute (5P20CA192993 and 5P20CA192991 PI: Sheffer).

Institutional Review Board Statement: The study was conducted according to the guidelines of the Declaration of Helsinki, and approved by the Institutional Review Boards of City University of New York (\#680011-1) and Roswell Park Comprehensive Cancer Center (\#BDR082917). Informed consent was obtained from all participants.

Informed Consent Statement: Informed consent was obtained from all subjects involved in the study.

Data Availability Statement: No new data were created or analyzed in this study. Data sharing is not applicable to this article.

Acknowledgments: The content is solely the responsibility of the authors and does not necessarily represent the official views of the National Institutes of Health.

Conflicts of Interest: The authors declare no conflict of interest.

\section{References}

1. WHO. WHO Report on the Global Tobacco Epidemic, 2017: Monitoring Tobacco Use and Prevention Policies; World Health Organization: Geneva, Switzerland, 2017.

2. Barlow, P.; McKee, M.; Reeves, A.; Galea, G.; Stuckler, D. Time-discounting and tobacco smoking: A systematic review and network analysis. Int. J. Epidemiol. 2017, 46, 860-869. [CrossRef]

3. Friedel, J.E.; DeHart, W.B.; Madden, G.J.; Odum, A.L. Impulsivity and cigarette smoking: Discounting of monetary and consumable outcomes in current and non-smokers. Psychopharmacology 2014, 231, 4517-4526. [CrossRef] [PubMed]

4. Öberg, M.; Jaakkola, M.S.; Prüss-Ustün, A.; Peruga, A.; Woodward, A.; World Health, O. Global Estimate of the Burden of Disease from Second-Hand Smoke/by Mattias Öberg...[et al]; World Health Organization: Geneva, Switzerland, 2010.

5. Oberg, M.; Jaakkola, M.S.; Woodward, A.; Peruga, A.; Prüss-Ustün, A. Worldwide burden of disease from exposure to second-hand smoke: A retrospective analysis of data from 192 countries. Lancet 2011, 377, 139-146. [CrossRef]

6. Rung, J.M.; Madden, G.J. Experimental reductions of delay discounting and impulsive choice: A systematic review and metaanalysis. J. Exp. Psychol. Gen. 2018, 147, 1349-1381. [CrossRef] [PubMed]

7. Rung, J.M.; Peck, S.; Hinnenkamp, J.; Preston, E.; Madden, G.J. Changing Delay Discounting and Impulsive Choice: Implications for Addictions, Prevention, and Human Health. Perspect. Behav. Sci. 2019, 42, 397-417. [CrossRef] [PubMed]

8. Stein, J.S.; Wilson, A.G.; Koffarnus, M.N.; Daniel, T.O.; Epstein, L.H.; Bickel, W.K. Unstuck in time: Episodic future thinking reduces delay discounting and cigarette smoking. Psychopharmacology 2016, 233, 3771-3778. [CrossRef]

9. ACS. Cancer Facts and Figures 2016; American Cancer Society: Atlanta, GA, USA, 2016.

10. U.S. Department of Health and Human Services. The Health Consequences of Smoking-50 Years of Progress. A Report of the Surgeon General; U.S. Department of Health and Human Services, Centers for Disease Control and Prevention, National Center for Chronic Disease Prevention and Health Promotion, Office on Smoking and Health: Atlanta, GA, USA, 2014.

11. Babb, S.; Malarcher, A.; Schauer, G.; Asman, K.; Jamal, A. Quitting Smoking Among Adults-United States, 2000-2015. MMWR Morb. Mortal Wkly. Rep. 2017, 65, 1457-1464. [CrossRef] [PubMed]

12. Rupprecht, L.E.; Smith, T.T.; Schassburger, R.L.; Buffalari, D.M.; Sved, A.F.; Donny, E.C. Behavioral Mechanisms Underlying Nicotine Reinforcement. In The Neuropharmacology of Nicotine Dependence; Springer International Publishing: Berlin/Heidelberg, Germany, 2015; pp. 19-53.

13. Perkins, K.A.; Karelitz, J.L. Reinforcement enhancing effects of nicotine via smoking. Psychopharmacology 2013, $228,479-486$. [CrossRef]

14. Ainslie, G. Specious reward: A behavioral theory of impulsiveness and impulse control. Psychol. Bull. 1975, 82, 463-496. [CrossRef] [PubMed]

15. Kirby, K.N. Bidding on the future: Evidence against normative discounting of delayed rewards. J. Exp. Psychol. General 1997, 126, 54-70. [CrossRef]

16. Logue, A.W. Research on self-control: An integrating framework. Behav. Brain Sci. 1988, 11, 665-709.

17. Mazur, J.E. An adjusting procedure for studying delayed reinforcement. In The Effect of Delay and of Intervening Events on Reinforcement Value, Quantitative Analyses of Behavior; Commons, M.L., Mazur, J.E., Nevin, J.A., Rachlin, H., Eds.; Lawrence Erlbaum Associates, Inc.: Hillsdale, NJ, USA, 1987; pp. 55-73.

18. Baker, F.; Johnson, M.W.; Bickel, W.K. Delay discounting in current and never-before cigarette smokers: Similarities and differences across commodity, sign, and magnitude. J. Abnorm. Psychol. 2003, 112, 382-392. [CrossRef] [PubMed]

19. Bickel, W.K.; Madden, G.J. A comparison of measures of relative reinforcing efficacy and behavioral economics: Cigarettes and money in smokers. Behav. Pharmacol. 1999, 10, 627-637. [CrossRef] [PubMed] 
20. Bickel, W.K.; Bickel, W.K.; Yi, R.; Kowal, B.P.; Gatchalian, K.M. Cigarette smokers discount past and future rewards symmetrically and more than controls: Is discounting a measure of impulsivity? Drug Alcohol Depend. 2008, 96, 256-262. [CrossRef] [PubMed]

21. Mitchell, S.H. Measures of impulsivity in cigarette smokers and non-smokers. Psychopharmacology 1999, 146, 455-464. [CrossRef] [PubMed]

22. Odum, A.L. Delay discounting: I'm a k, you're a k. J. Exp. Anal. Behav. 2011, 96, 427-439.

23. Reynolds, B. Do high rates of cigarette consumption increase delay discounting? A cross-sectional comparison of adolescent smokers and young-adult smokers and nonsmokers. Behav. Process. 2004, 67, 545-549. [CrossRef]

24. Krishnan-Sarin, S.; Reynolds, B.; Duhig, A.M.; Smith, A.; Liss, T.; McFetridge, A.; Cavallo, D.A.; Carroll, K.M.; Potenza, M.N. Behavioral impulsivity predicts treatment outcome in a smoking cessation program for adolescent smokers. Drug Alcohol Depend. 2007, 88, 79-82.

25. MacKillop, J.; Kahler, C.W. Delayed reward discounting predicts treatment response for heavy drinkers receiving smoking cessation treatment. Drug Alcohol Depend. 2009, 104, 197-203. [CrossRef]

26. Sheffer, C.; Mackillop, J.; McGeary, J.; Landes, R.; Carter, L.; Yi, R.; Jones, B.; Christensen, D.; Stitzer, M.; Jackson, L.; et al. Delay discounting, locus of control, and cognitive impulsiveness independently predict tobacco dependence treatment outcomes in a highly dependent, lower socioeconomic group of smokers. Am. J. Addict. 2012, 21, 221-232. [CrossRef]

27. Sheffer, C.E.; Christensen, D.R.; Landes, R.; Carter, L.P.; Jackson, L.; Bickel, W.K. Delay discounting rates: A strong prognostic indicator of smoking relapse. Addict. Behav. 2014, 39, 1682-1689. [CrossRef] [PubMed]

28. Stanger, C.; Ryan, S.R.; Fu, H.; Landes, R.D.; Jones, B.A.; Bickel, W.K.; Budney, A.J. Delay discounting predicts adolescent substance abuse treatment outcome. Exp. Clin. Psychopharmacol. 2012, 20, 205-212. [CrossRef]

29. Yoon, J.H.; Higgins, S.T.; Heil, S.H.; Sugarbaker, R.J.; Thomas, C.S.; Badger, G.J. Delay discounting predicts postpartum relapse to cigarette smoking among pregnant women. Exp. Clin. Psychopharmacol. 2007, 15, 176-186. [CrossRef] [PubMed]

30. Bickel, W.K.; Yi, R.; Landes, R.D.; Hill, P.F.; Baxter, C. Remember the future: Working memory training decreases delay discounting among stimulant addicts. Biol. Psychiatry 2011, 69, 260-265. [CrossRef]

31. Black, A.C.; Rosen, M.I. A money management-based substance use treatment increases valuation of future rewards. Addict. Behav. 2011, 36, 125-128. [CrossRef] [PubMed]

32. Sheffer, C.E.; Prashad, N.; Lunden, S.; Malhotra, R.; O'Connor, R.J. To smoke or not to smoke: Does delay discounting affect the proximal choice to smoke? Subst. Use Misuse 2019, 54, 1237-1246. [CrossRef] [PubMed]

33. Bickel, W.K.; George Wilson, A.; Franck, C.T.; Terry Mueller, E.; Jarmolowicz, D.P.; Koffarnus, M.N.; Fede, S.J. Using crowdsourcing to compare temporal, social temporal, and probability discounting among obese and non-obese individuals. Appetite 2014, 75, 82-89. [CrossRef]

34. Athamneh, L.N.; Stein, J.S.; Bickel, W.K. Will delay discounting predict intention to quit smoking? Exp. Clin. Psychopharmacol. 2017, 25, 273-280. [CrossRef]

35. Koffarnus, M.N.; Jarmolowicz, D.P.; Mueller, E.T.; Bickel, W.K. Changing delay discounting in the light of the competing neurobehavioral decision systems theory: A review. J. Exp. Anal. Behav. 2013, 99, 32-57. [CrossRef]

36. Daniel, T.O.; Stanton, C.M.; Epstein, L.H. The future is now: Reducing impulsivity and energy intake using episodic future thinking. Psychol. Sci. 2013, 24, 2339-2342. [CrossRef]

37. Dassen, F.C.M.; Jansen, A.; Nederkoorn, C.; Houben, K. Focus on the future: Episodic future thinking reduces discount rate and snacking. Appetite 2016, 96, 327-332. [CrossRef] [PubMed]

38. O'Neill, J.; Daniel, T.O.; Epstein, L.H. Episodic future thinking reduces eating in a food court. Eat. Behav. 2016, 20, 9-13. [CrossRef]

39. Snider, S.E.; LaConte, S.M.; Bickel, W.K. Episodic Future Thinking: Expansion of the Temporal Window in Individuals with Alcohol Dependence. Alcohol Clin. Exp. Res. 2016, 40, 1558-1566. [CrossRef]

40. Sze, Y.Y.; Daniel, T.O.; Kilanowski, C.K.; Collins, R.L.; Epstein, L.H. Web-Based and Mobile Delivery of an Episodic Future Thinking Intervention for Overweight and Obese Families: A Feasibility Study. JMIR Mhealth Uhealth 2015, 3, e97. [CrossRef]

41. Sheffer, C.E.; Mackillop, J.; Fernandez, A.; Christensen, D.; Bickel, W.K.; Johnson, M.W.; Panissidi, L.; Pittman, J.; Franck, C.T.; Williams, J.; et al. Initial examination of priming tasks to decrease delay discounting. Behav. Process. 2016, 128, 144-152. [CrossRef]

42. Shevorykin, A.; Pittman, J.C.; Bickel, W.K.; O'Connor, R.J.; Malhotra, R.; Prashad, N.; Sheffer, C.E. Primed for Health: Future Thinking Priming Decreases Delay Discounting. Health Behav. Policy Rev. 2019, 6, 363-377. [CrossRef]

43. Barutchu, A.; Sahu, A.; Humphreys, G.W.; Spence, C. Multisensory processing in event-based prospective memory. Acta Psychol. 2019, 192, 23-30. [CrossRef]

44. Barutchu, A.; Spence, C.; Humphreys, G.W. Multisensory enhancement elicited by unconscious visual stimuli. Exp. Brain Res. 2018, 236, 409-417. [CrossRef]

45. Elgendi, M.; Kumar, P.; Barbic, S.; Howard, N.; Abbott, D.; Cichocki, A. Subliminal Priming-State of the Art and Future Perspectives. Behav. Sci. 2018, 8, 54. [CrossRef]

46. Peters, J.; Buchel, C. Episodic future thinking reduces reward delay discounting through an enhancement of prefrontalmediotemporal interactions. Neuron 2010, 66, 138-148. [CrossRef]

47. Mitchell, S.H.; Wilson, V.B. Differences in delay discounting between smokers and nonsmokers remain when both rewards are delayed. Psychopharmacology 2012, 219, 549-562. [CrossRef]

48. Bickel, W.K.; Landes, R.D.; Kurth-Nelson, Z.; Redish, A.D. A Quantitative Signature of Self-Control Repair. Clin. Psychol. Sci. 2014, 2, 685-695. 
49. Bickel, W.K.; Quisenberry, A.J.; Snider, S.E. Does impulsivity change rate dependently following stimulant administration? A translational selective review and re-analysis. Psychopharmacology 2016, 233, 1-18. [CrossRef]

50. Oldham, P.D. A note on the analysis of repeated measurements of the same subjects. J. Chronic Dis. 1962, 15, 969-977. [CrossRef]

51. Quisenberry, A.J.; Snider, S.E.; Bickel, W.K. The Return of Rate Dependence. Behav. Anal. 2016, 16, 215-220. [CrossRef] [PubMed]

52. Snider, S.E.; Quisenberry, A.J.; Bickel, W.K. Order in the absence of an effect: Identifying rate-dependent relationships. Behav. Process. 2016, 127, 18-24. [CrossRef]

53. Buhrmester, M.; Kwang, T.; Gosling, S.D. Amazon's Mechanical Turk: A New Source of Inexpensive, Yet High-Quality, Data? Perspect. Psychol. Sci. 2011, 6, 3-5. [CrossRef]

54. Crump, M.J.; McDonnell, J.V.; Gureckis, T.M. Evaluating Amazon's Mechanical Turk as a tool for experimental behavioral research. PLoS ONE 2013, 8, e57410. [CrossRef]

55. Paolacci, G.; Chandler, J.; Ipeirotis, P.G. Running experiments on Amazon Mechanical Turk. Judgm. Decis. Mak. 2010, 5, 411-419.

56. Ross, J.; Irani, I.; Silberman, M.; Zaldivar, A.; Tomlinson, B. Who are the Crowdworkers? Shifting Demographics in Amazon Mechanical Turk. In Proceedings of the Conference on Human Factors in Computing Systems, Atlanta, GA, USA, 10-15 April 2010; pp. 2863-2872.

57. Wheeler, S.C.; Demarree, K.G.; Petty, R.E. Understanding the role of the self in prime-to-behavior effects: The Active-Self account. Pers. Soc. Psychol. Rev. 2007, 11, 234-261. [CrossRef]

58. Fong, G.T.; Hall, P.A. The importance of time perspective in predicting, understanding, and reducing health risk behaviors among adolescents. In Reducing Adolescent Risk: Toward an Integrated Approach; Romer, D., Ed.; Sage: Newbury Park, CA, USA, 2003.

59. Adler, N.; Stewart, J. The MacArthur Scale of Subjective Social Status; MacArthur Research Network on SES \& Health: San Francisco, CA, USA, 2007.

60. Koffarnus, M.N.; Bickel, W.K. A 5-trial adjusting delay discounting task: Accurate discount rates in less than one minute. Exp. Clin. Psychopharmacol. 2014, 22, 222-228. [CrossRef]

61. Chiolero, A.; Paradis, G.; Rich, B.; Hanley, J.A. Assessing the Relationship between the Baseline Value of a Continuous Variable and Subsequent Change Over Time. Front. Public Health 2013, 1, 29. [CrossRef] [PubMed]

62. Hayes, A.F. Introduction to Mediation, Moderation, and Conditional Process Analysis: A Regression-Based Approach; Guilford Publications: New York, NY, USA, 2017.

63. Nunes, E.V.; Pavlicova, M.; Hu, M.-C.; Campbell, A.N.; Miele, G.; Hien, D.; Klein, D.F. Baseline Matters: The Importance of Covariation for Baseline Severity in the Analysis of Clinical Trials. Am. J. Drug Alcohol Abus. 2011, 37, 446-452. [CrossRef]

64. Selby, J.V.; Beal, A.C.; Frank, L. The Patient-Centered Outcomes Research Institute (PCORI) National Priorities for Research and Initial Research Agenda. JAMA 2012, 307, 1583-1584.

65. Snider, S.E.; Deshpande, H.U.; Lisinski, J.M.; Koffarnus, M.N.; LaConte, S.M.; Bickel, W.K. Working Memory Training Improves Alcohol Users' Episodic Future Thinking: A Rate-Dependent Analysis. Biol. Psychiatry Cogn. Neurosci. Neuroimaging 2018, 3 , 160-167. [CrossRef]

66. Cheng, H.G.; Phillips, M.R. Secondary Analysis of Existing Data: Opportunities and Implementation. Shanghai Arch. Psychiatry 2014, 26, 371-375. 